\title{
An analytical approach for LQR design for improving damping performance of multi-machine power system
}

\author{
Sreenivas Uravakonda', Vijaya Kumar Mallapu², Venkateswara Reddy Annapu Reddy ${ }^{3}$ \\ ${ }^{1}$ Department of Electrical and Electronics Engineering, Faculty of Engineering, Srinivasa Ramanujan Institute of Technology, \\ Rotarypuram, Jawaharlal Nehru Technological University, Anantapur, India \\ ${ }^{2}$ Department of Electrical and Electronics Engineering, Faculty of Engineering, Jawaharlal Nehru Technological University, \\ Anantapur, India \\ ${ }^{3}$ Department of Electrical and Electronics Engineering, Faculty of Engineering, Sai Rajeswari Institute of Technology, Proddatur, \\ Jawaharlal Nehru Technological University, Anantapur, India
}

\begin{abstract}
Article Info
Article history:

Received Jun 2, 2021

Revised Nov 24, 2021

Accepted Nov 27, 2021

Keywords:

Analytical approach

Low-frequency oscillations

LQR

Optimal control theory

Power system stabilizer

ABSTRACT

In a multi-machine environment, the inter-area low-frequency oscillations induced due to small perturbation(s) has a significant adverse effect on the maximum limit of power transfer capacity of power system. Conventionally, to address this issue, power systems were equipped with lead-lag power system stabilizers (CPSS) for damping oscillations of low-frequency. In recent years the research was directed towards optimal control theory to design an optimal linear-quadratic-regultor (LQR) for stabilizing power system against the small perturbation(s). The optimal control theory provides a systematic way to design an optimal LQR with sufficient stability margins. Hence, LQR provides an improved level of performance than CPSS over broad-range of operating conditions. The process of designing of optimal LQR involves optimization of associated state (Q) and control (R) weights. This paper presents an analytical approach (AA) to design an optimal LQR by deriving algebraic equations for evaluating optimal elements for weight matrix ' $Q$ '. The performance of the proposed LQR is studied on an IEEE test system comprising 4-generators and 10-busbars.
\end{abstract}

This is an open access article under the CC BY-SA license.

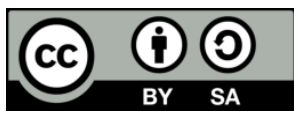

\section{Corresponding Author:}

Sreenivas Uravakonda

Department of Electrical and Electronics Engineering, Faculty of Engineering

Srinivasa Ramanujan Institute of Technology, Rotarypuram, Jawaharlal Nehru Technological University

Anantapur, Ananthapuramu, Andhra Pradesh, India

Email: uravakonda.sreenivas@gmail.com

\section{INTRODUCTION}

To enhance the damping performance of an electrical power system against small disturbance(s), an excitation-based power system stabilizer (CPSS) is extensively used around the world. Although the CPSSs have been used widely for satisfactorily damping local-mode low-frequency oscillations, the outcome of CPSS may not be the best possible because of the intuitive nature of the tuning process and restrictive assumptions made. Later, the research was directed towards optimal control theory to develop an optimal state-variable feedback gain controller i.e. linear-quadratic-regultor (LQR) for stabilizing power systems against small perturbation(s). Consequently, reports [1]-[10] have appeared in the literature concerning the application of optimal LQR for stabilizing power systems.

In the referred papers [1]-[10], the design of LQR is based on the following sequential process: i) The control $(R)$ and state $(Q)$ weights are chosen as diagonal matrices; ii) The state weighing matrix $Q$ is assigned numerical values arbitrarily by an iterative procedure; iii) Optimal LQR is determined; and 
iv) Closed-loop performance of an electrical power system equipped with optimal LQR is investigated. If the system performance is not satisfactory, the entire process has to be repeated until satisfactory damping performance is obtained. This trial-and-error (T\&E) method doesn't offer a systematic way of tuning $Q$; hence it is cumbersome, burdensome, and time-consuming.

On the other hand, in recent decades, other researchers had been developed evolutionary algorithms to design optimal LQR [11]-[17]. In the referred papers [11]-[17], different evolutionary algorithms such as genetic algorithm (GA), particle swam optimization (PSO), big bang-big crunch (BB-BC), ant colony optimization (ACO), real-coded genetic algorithm, differential evolution (D.E.) algorithm, and Jaya algorithm are reported to design optimal LQR. And in the references [18]-[25], Gbest-guided artificial bee colony algorithm, backtracking search algorithm, adaptive backstepping approach, Whale optimization algorithm, an improved whale optimization technique, modified shuffled frog leaping (MSFL) algorithm, model reference self-tuning Takaji-Sugeno fractional-order proportional-integral-derivative (TSMFOPID) control technique and evolutionary programming based optimisation technique respectively for tuning CPSS. But, the evolutionary techniques are i) highly dependent on evolutionary algorithms to optimize and ii) computation time is more; hence their use is restricted for solving optimization problems.

All these issues were addressed in this paper by proposing an analytical approach (AA) to tune LQR. The proposed technique of tuning LQR explores the correlation between the Lagrange-multiplier optimization technique and the algebraic-Riccati-equation (ARE). The proposed approach has the following advantages: i) It takes negligible time to tune LQR with the aid of derived algebraic equations; ii) It translates the performance objectives of the system from time-domain into cost-function; and iii) It enhances the robustness of the power system as $Q$ varies in line with the operating condition. The proposed methodology explores its modular approach in tuning LQR. However, the design of a robust and decentralized LQR controller becomes impractical due to the non-availability of facilities to measure state variables (especially the rotor angle) in most multi-machine power systems (MMPS). This issue is addressed by considering the secondary voltage of transformer as a reference rather than infinite-bus voltage in modelling the power system [26].

\section{MODELLING OF POWER SYSTEM}

An IEEE test system comprising 4-generators and 10-busbars shown in Figure 1 is chosen for the study. This section deals with the modelling and stability analysis of electrical power system. The modelling of power system is done based on modified version of Heffron-Phillips model [26]. This facilitates the proposed optimal LQR more practical.

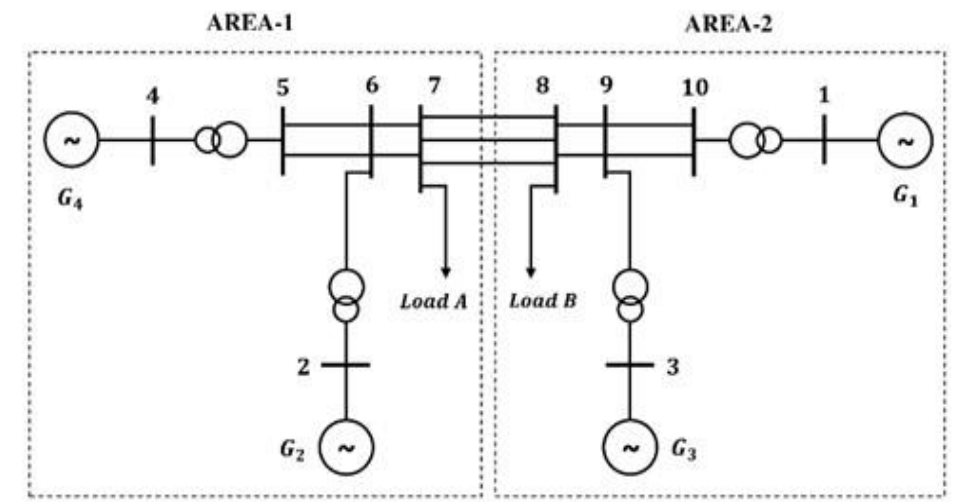

Figure 1. Single-line representation of 4-Generator and 10-Bus system

The linearized dynamic equations of an $i^{\text {th }}$-generator of power system are;

$$
\begin{aligned}
& \Delta \dot{\delta_{s_{l}}}=\left(\omega_{B_{i}} \Delta S_{m_{i}}-\Delta \theta_{s_{i}}\right) \\
& \Delta \dot{S}_{m_{l}}=\frac{1}{2 H_{i}}\left(-G_{1_{i}} \Delta \delta_{s_{i}}-G_{2_{i}} \Delta E_{q_{i}}^{\prime}-G_{v_{1_{i}}} \Delta V_{s_{i}}-D_{i} \Delta S_{m_{i}}\right) \\
& \Delta \dot{E_{q_{l}}^{\prime}}=\frac{1}{T_{d o_{i}}^{\prime}}\left\{\Delta E_{f d_{i}}-G_{4_{i}} \Delta \delta_{s_{i}}-G_{v_{2_{i}}} \Delta V_{s_{i}}-\frac{\Delta E_{q_{i}}^{\prime}}{G_{3_{i}}}\right\}
\end{aligned}
$$




$$
\Delta \dot{E}_{f d_{\imath}}=\left\{\frac{K_{E_{i}}}{T_{E_{i}}}\left(\Delta V_{p s s_{i}}-G_{5_{i}} \Delta \delta_{s_{i}}-G_{6_{i}} \Delta E_{q_{i}}^{\prime}-G_{v_{3_{i}}} \Delta V_{s_{i}}\right)-\frac{\Delta E_{q_{i}}^{\prime}}{T_{E_{i}}}\right\}
$$

The state-space representation of (1)-(4) is;

$$
\begin{aligned}
& \dot{x}_{i}=A_{g_{i}} x_{i}+B_{g_{i}} u_{i}+B_{1_{i}} u_{1_{i}} \\
& y_{i}=C_{g_{i}} x_{i}+D_{g_{i}} u_{i}
\end{aligned}
$$

Since the coefficients $G_{v_{1_{i}}}, G_{v_{2_{i}}}, G_{v_{3_{i}}}$ are negligibly small, the (5) and (6) are reduced to;

$$
\begin{aligned}
& \dot{x}_{i}=A_{g_{i}} x_{i}+B_{g_{i}} u_{i} \\
& y_{i}=C_{g_{i}} x_{i}+D_{g_{i}} u_{i}
\end{aligned}
$$

The Laplace's transformation of the state-space model of an $i^{\text {th }}$-generator is;

$$
\begin{aligned}
& s \Delta E_{q_{i}}^{\prime}(s)=-\frac{1}{G_{3_{i}} T_{d o_{i}}^{\prime}} \Delta E_{q_{i}}^{\prime}(s)-\frac{G_{4_{i}}}{T_{d o_{i}}^{\prime}} \Delta \delta_{s_{i}}(s)+\frac{1}{T_{d o_{i}}^{\prime}} \Delta E_{f d_{i}}(s) \\
& s \Delta \delta_{s_{i}}(s)=\Delta \omega_{i}(s) \\
& s \Delta \omega_{i}(s)=\left\{\frac{\omega_{B_{i}}}{2 H_{i}} \Delta T_{m_{i}}(s)-\frac{\omega_{B_{i}}}{2 H_{i}}\left[G_{1_{i}} \Delta \delta_{s_{i}}(s)+G_{2_{i}} \Delta E_{q_{i}}^{\prime}(s)\right]-\frac{\omega_{B_{i}}}{2 H_{i}} D_{i} \Delta \omega_{i}(s)\right\} \\
& s \Delta E_{f d_{i}}(s)=\left\{-\frac{1}{T_{E_{i}}} \Delta E_{f d_{i}}(s)-\frac{K_{E_{i}}}{T_{E_{i}}}\left[G_{5_{i}} \Delta \delta_{s_{i}}(s)+G_{6_{i}} \Delta E_{q_{i}}^{\prime}(s)\right]+\frac{K_{E_{i}}}{T_{E_{i}}} \Delta V_{r e f_{i}}(s)\right\}
\end{aligned}
$$

Under the assumption that, $\Delta V_{\text {ref }_{i}}=0$; simplification of (9) and (12) yields (13);

$$
\Delta E_{q_{i}}^{\prime}(s)=-\frac{\left[G_{4_{i}}\left(1+s T_{E_{i}}\right)+K_{E_{i}} G_{5_{i}}\right] G_{3_{i}}}{\left[\left(1+s G_{3_{i}} T_{d o_{i}}^{\prime}\right)\left(1+s T_{E_{i}}\right)+K_{E_{i}} G_{6_{i}} G_{3_{i}}\right]} \Delta \delta(s)
$$

The Laplace's transformation of electrical torque of an $i^{\text {th }}$-generator is;

$$
\Delta T_{e_{i}}(s)=\left[G_{1_{i}} \Delta \delta_{s_{i}}(s)+G_{2_{i}} \Delta E_{q_{i}}^{\prime}(s)\right]
$$

By substituting (13) in (14) yields (15),

$$
\Delta T_{e_{i}}(s)=\left\{G_{1_{i}}-\frac{\left[G_{4_{i}}\left(1+s T_{E_{i}}\right)+K_{E_{i}} G_{5_{i}}\right] G_{3_{i}} G_{2_{i}}}{\left[\left(1+s G_{3_{i}} T_{d o_{i}}^{\prime}\right)\left(1+s T_{E_{i}}\right)+K_{E_{i}} G_{6_{i}} G_{3_{i}}\right]}\right\} \Delta \delta_{s_{i}}(s)=G_{i}(s) * \Delta \delta_{s_{i}}(s)
$$

\section{PROBLEM STATEMENT AND ANALYTICAL APPROACH OF DESIGNING LQR}

This section explores the analytical approach of tuning state-weighing matrix $(Q)$ associated with LQR. The feedback control law to minimize the cost function ' $J(u)$ ' of linear-quadratic-regulator is given by (16).

$$
u(t)=-K x(t)
$$

The cost function of LQR is given by (17).

$$
J(u)=\int_{0}^{\infty}\left[x^{T}(t) \cdot Q \cdot x(t)+u^{T}(t) \cdot R \cdot u(t)\right] d t
$$

The Lagrange-multiplier optimization technique for optimizing linear state feedback gain vector $(K)$ is,

$$
K=R^{-1} B^{T} P
$$

where, $P$ is the matrix solution to the following reduced algebraic-Reccati-equation (ARE).

$$
A^{T} P+P A+Q-P B R^{-1} B^{T} P=0
$$

The canonical form of electrical power system that is controllable [27] is given by; 


$$
\begin{aligned}
& \dot{x}=\hat{A} x+\hat{B} u \\
& y=\hat{C} x+\widehat{D} u
\end{aligned}
$$

where,

$$
\begin{aligned}
\hat{A} & =\left[\begin{array}{cccc}
0 & 1 & 0 & 0 \\
0 & 0 & 1 & 0 \\
0 & 0 & 0 & 1 \\
A_{41} & A_{42} & A_{43} & A_{44}
\end{array}\right] \\
\hat{B} & =\left[\begin{array}{llll}
0 & 0 & 0 & B_{41}
\end{array}\right]^{T} \\
\hat{C} & =\left[\begin{array}{llll}
0 & C_{12} & 0 & 0
\end{array}\right] \\
\widehat{D} & =\left[\begin{array}{ll}
0
\end{array}\right]
\end{aligned}
$$

The (19) in accordance with controllable canonical form of power system becomes,

$$
\hat{A}^{T} P+P \hat{A}+Q-P \hat{B} R^{-1} \hat{B}^{T} P=0
$$

where $Q, R$ and $P$ are defined as (27)-(29).

$$
\begin{aligned}
Q & =\left[\begin{array}{cccc}
q_{1} & 0 & 0 & 0 \\
0 & q_{2} & 0 & 0 \\
0 & 0 & q_{3} & 0 \\
0 & 0 & 0 & q_{4}
\end{array}\right] \\
R & =[r] \\
P & =\left[\begin{array}{llll}
p_{11} & p_{12} & p_{13} & p_{14} \\
p_{12} & p_{22} & p_{23} & p_{24} \\
p_{13} & p_{23} & p_{33} & p_{34} \\
p_{14} & p_{24} & p_{34} & p_{44}
\end{array}\right]
\end{aligned}
$$

The (18) in accordance with controllable canonical form of power system becomes,

$$
K=R^{-1} \hat{B}^{T} P=\frac{B_{41}}{r}\left[\begin{array}{llll}
p_{14} & p_{24} & p_{34} & p_{44}
\end{array}\right]
$$

For closed-loop systems, the actual characteristic equation is given by (31),

$$
|s I-\hat{A}+\hat{B} K|=0
$$

By substituting (22), (23) and (30) in (31) yields (32),

$$
\left(s^{4}+s^{3}\left(\frac{B_{41}^{2} p_{44}}{r}-A_{44}\right)+s^{2}\left(\frac{B_{41}^{2} p_{34}}{r}-A_{43}\right)+s\left(\frac{B_{41}^{2} p_{24}}{r}-A_{42}\right)+\left(\frac{B_{41}^{2} p_{14}}{r}-A_{41}\right)\right)=0
$$

For $4^{\text {th }}$-order systems, the desired characteristic equation is (33),

$$
\left(s^{4}+4 \xi \omega_{n} s^{3}+2 \omega_{n}^{2}\left(2 \xi^{2}+1\right) s^{2}+4 \xi \omega_{n}^{3} s+\omega_{n}^{4}\right)=0
$$

The $4^{\text {th }}$-row elements of matrix $P$ are given by the following (34)-(37);

$$
\begin{aligned}
& p_{14}=\left(\omega_{n}^{4}+A_{41}\right) \frac{r}{B_{41}^{2}} \\
& p_{24}=\left(4 \xi \omega_{n}^{3}+A_{42}\right) \frac{r}{B_{41}^{2}} \\
& p_{34}=\left[2 \omega_{n}^{2}\left(2 \xi^{2}+1\right)+A_{43}\right] \frac{r}{B_{41}^{2}} \\
& p_{44}=\left(4 \xi \omega_{n}+A_{44}\right) \frac{r}{B_{41}^{2}}
\end{aligned}
$$


with the aid of ARE and (34)-(37) following equations are derived to get optimal $Q$.

$$
\begin{aligned}
& \frac{q_{1}}{r}=\frac{1}{B_{41}^{2}}\left(\omega_{n}^{8}-A_{41}^{2}\right) \\
& \frac{q_{2}}{r}=\frac{1}{B_{41}^{2}}\left[2 A_{41} A_{43}-A_{42}^{2}+4 \omega_{n}^{6}\left(2 \xi^{2}-1\right)\right] \\
& \frac{q_{3}}{r}=\frac{1}{B_{41}^{2}}\left\{2\left[A_{41}+A_{42} A_{44}+3 \omega_{n}^{4}+8 \omega_{n}^{4} \xi^{2}\left(\xi^{2}-1\right)\right]-A_{43}^{2}\right\} \\
& \frac{q_{4}}{r}=\frac{1}{B_{41}^{2}}\left[4 \omega_{n}^{2}\left(2 \xi^{2}-1\right)-2 A_{43}-A_{44}^{2}\right]
\end{aligned}
$$

The (38)-(41) are the outcome of proposed analytical approach for designing an optimal LQR for specified natural frequency $\left(\omega_{n}\right)$, damping $\operatorname{ratio}(\xi)$, and scalar quantity $R$.

\section{DESCRIPTION OF POWER SYSTEM}

The loads of the IEEE test system considered are modelled as constant impedances. The total connected load in the system is $2734 \mathrm{MW}$. The machine data, line data, load flow data, and automatic voltage regulator (AVR) \& excitation-system data of the test system are taken from [28]. The symmetric base system consists of two identical areas connected through a relatively weak tie line. Each area comprises two generating units with equal power outputs. The electro-mechanical modes of oscillation present in the system are modes present with in the plant (inter-plant modes) and low frequency inter-area mode.

\section{RESULTS AND DISCUSSION}

Here, a comprehensive discussion is made on results obtained against small disturbances i) step change in the voltage, ii) step change in the electrical torque under different loading conditions nominal load, light load, and heavy load. The comparative damping performances of generators that are fitted with either LQR tuned through analytical approach or LQR tuned via trial and error method or CPSS are shown in Figures 2-4.

\subsection{Case1: Nominal load}

In this case, all the generators are assumed to be loaded with their respective nominal loads. The Figure 2 shows the variation in slip $\left(S_{m}\right)$ for $10 \%$ step increase in torque at generator $G_{4}$ with tie-line power flow of $400 \mathrm{MW}$. It is observed that, the generator $G_{4}$ equipped with proposed LQR exhibits much superior damping performance than its counter parts. The same is in the case for generators $G_{1}, G_{2}$, and $G_{3}$. The settling times of generators noted from Figure 2 are tabulated in Table 1.
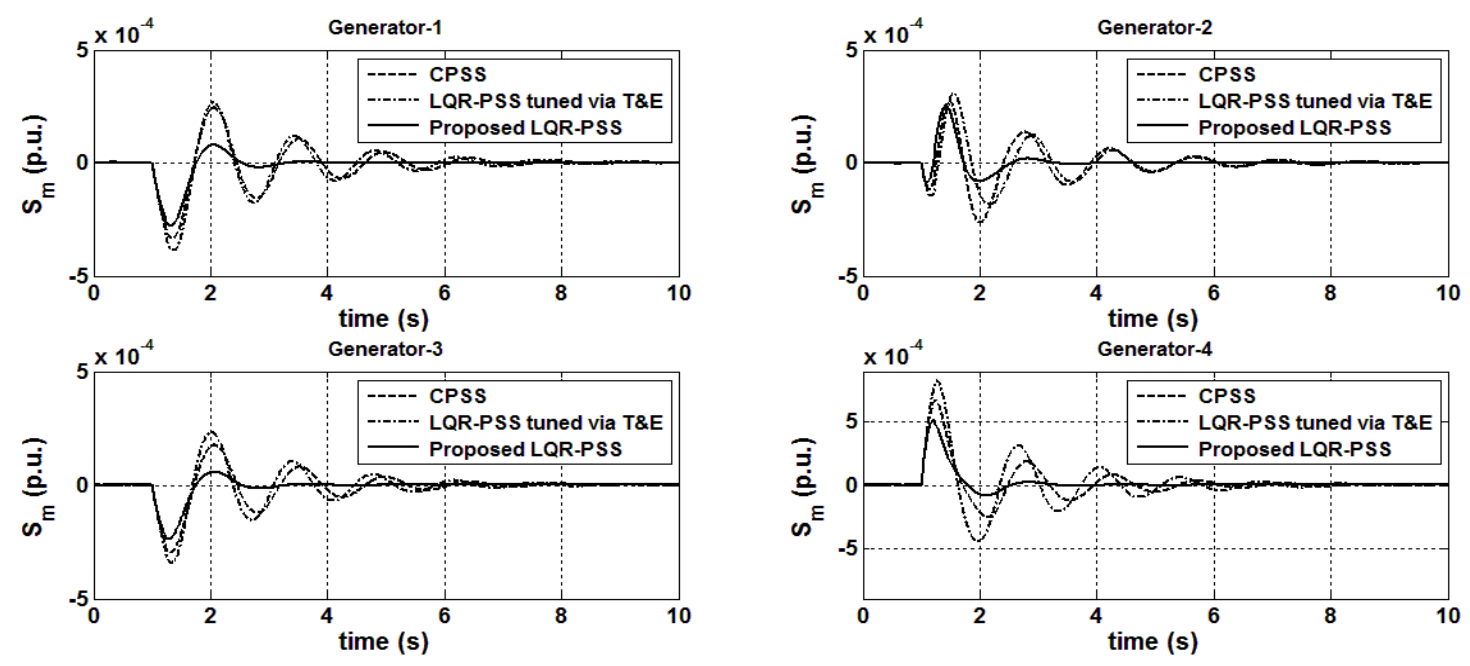

Figure 2. Variation in $\operatorname{slip}\left(S_{m}\right)$ when generator $G_{4}$ operating at nominal load is subjected to $10 \%$ increase in torque with tie line power flow of $400 \mathrm{MW}$ 
Table 1 . Settling time: nominal load: $10 \%$ step increase in torque at generator $G_{4}$

\begin{tabular}{cccc}
\hline \multirow{2}{*}{ Gen. No. } & \multicolumn{3}{c}{ Settling time (Sec.) } \\
& LPS & LQR tuned via T\&E method & Proposed LQR tuned via AA \\
\hline$G_{1}$ & 8.6 & 8.6 & 2.6 \\
$G_{2}$ & 8.6 & 8.6 & 2.6 \\
$G_{3}$ & 8.6 & 8.6 & 2.6 \\
$G_{4}$ & 8.6 & 8.6 & 2.6 \\
\hline
\end{tabular}

\subsection{Case2: Light load}

Here, all the generators are assumed to be loaded to $80 \%$ of their respective nominal loads. The Figure 3 shows the variation in slip $\left(S_{m}\right)$ for $10 \%$ step decrease in reference voltage at generator $G_{l}$ with tieline power flow of $100 \mathrm{MW}$. The generator $G_{1}$ equipped with proposed LQR settles at 1.9 Sec. with negligible overshoot and no undershoots after the disturbance. The same is in the case for generators $G_{2}, G_{3}$, and $G_{4}$. The settling times of generators noted from Figure 3 are tabulated in Table 2.
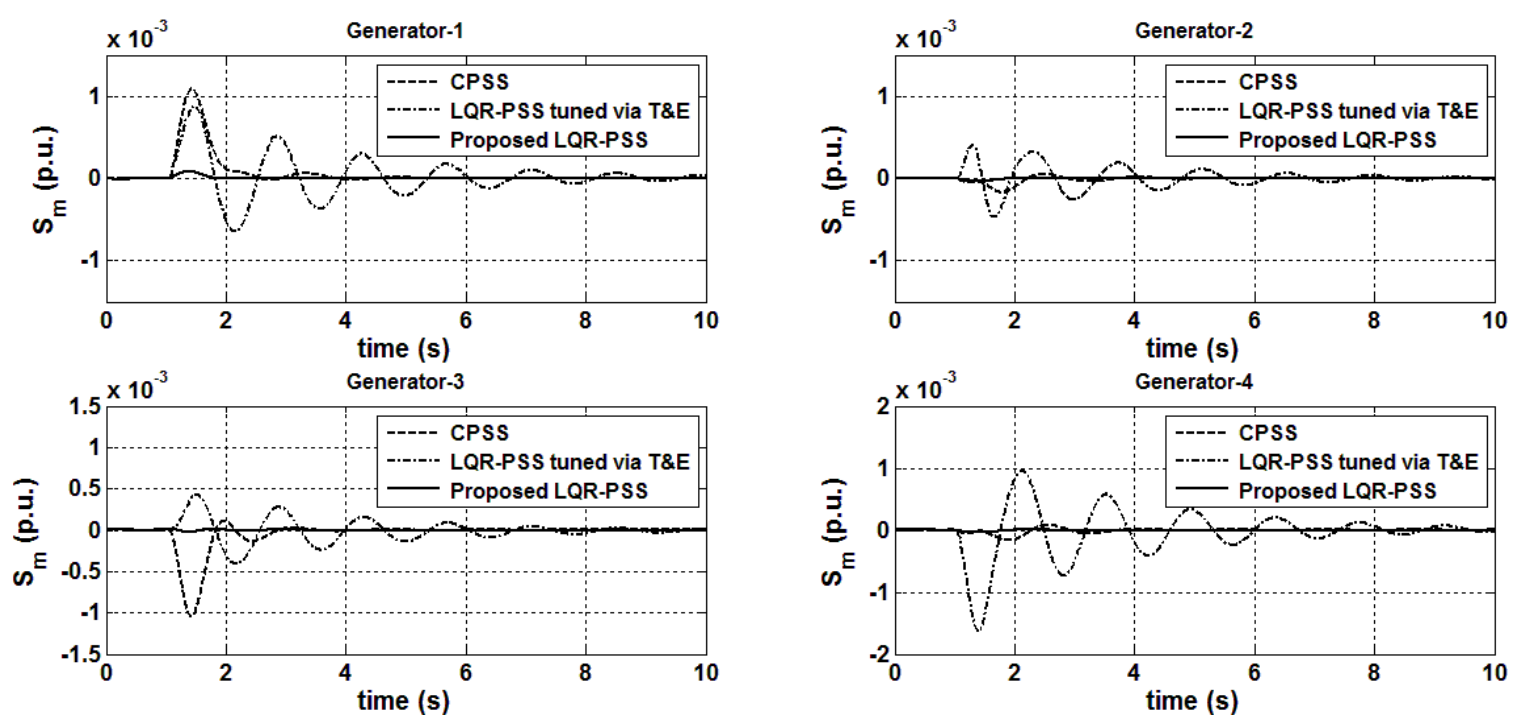

Figure 3. Variation in slip $\left(S_{m}\right)$ when generator $G_{l}$ operating at $80 \%$ of nominal load is subjected to $10 \%$ decrease in voltage with tie line power flow of $100 \mathrm{MW}$

Table 2. Settling time: light load: $10 \%$ step decrease in reference voltage at generator $G_{l}$

\begin{tabular}{cccc}
\hline \multirow{2}{*}{ Gen. No. } & \multicolumn{3}{c}{ Settling time (Sec.) } \\
& CPSS & LQR tuned via T\&E method & Proposed LQR tuned via AA \\
\hline$G_{1}$ & 4.2 & 10.4 & 1.9 \\
$G_{2}$ & 4.2 & 10.4 & 1.9 \\
$G_{3}$ & 4.2 & 10.4 & 1.9 \\
$G_{4}$ & 4.2 & 10.4 & 1.9 \\
\hline
\end{tabular}

\subsection{Case3: Heavy load}

In this case, all the generators are assumed to be loaded to $120 \%$ of their respective nominal loads. The Figure 4 shows the variation in slip $\left(S_{m}\right)$ for $10 \%$ step increase in reference voltage at generator $G_{3}$ with tie line power flow of $400 \mathrm{MW}$. In this case; after the disturbance, the generator $G_{3}$ equipped with proposed LQR settles in 2.2 Sec. with no overshoot and negligible undershoot, whereas it is $10.6 \mathrm{Sec}$. and 8.8 Sec. when $G_{3}$ is equipped with CPSS and LQR tuned via trial-and error method respectively. The settling times of generators noted from Figure 4 are tabulated in Table 3.

Table 3. Settling time: heavy load: $10 \%$ step increase in reference voltage at generator $G_{3}$

\begin{tabular}{cccc}
\hline \multirow{2}{*}{ Gen. No. } & \multicolumn{3}{c}{ Settling time (Sec.) } \\
& CPSS & LQR tuned via T\&E method & Proposed LQR tuned via AA \\
\hline$G_{1}$ & 10.6 & 8.8 & 2.2 \\
$G_{2}$ & 10.6 & 8.8 & 2.2 \\
$G_{3}$ & 10.6 & 8.8 & 2.2 \\
$G_{4}$ & 10.6 & 8.8 & 2.2 \\
\hline
\end{tabular}



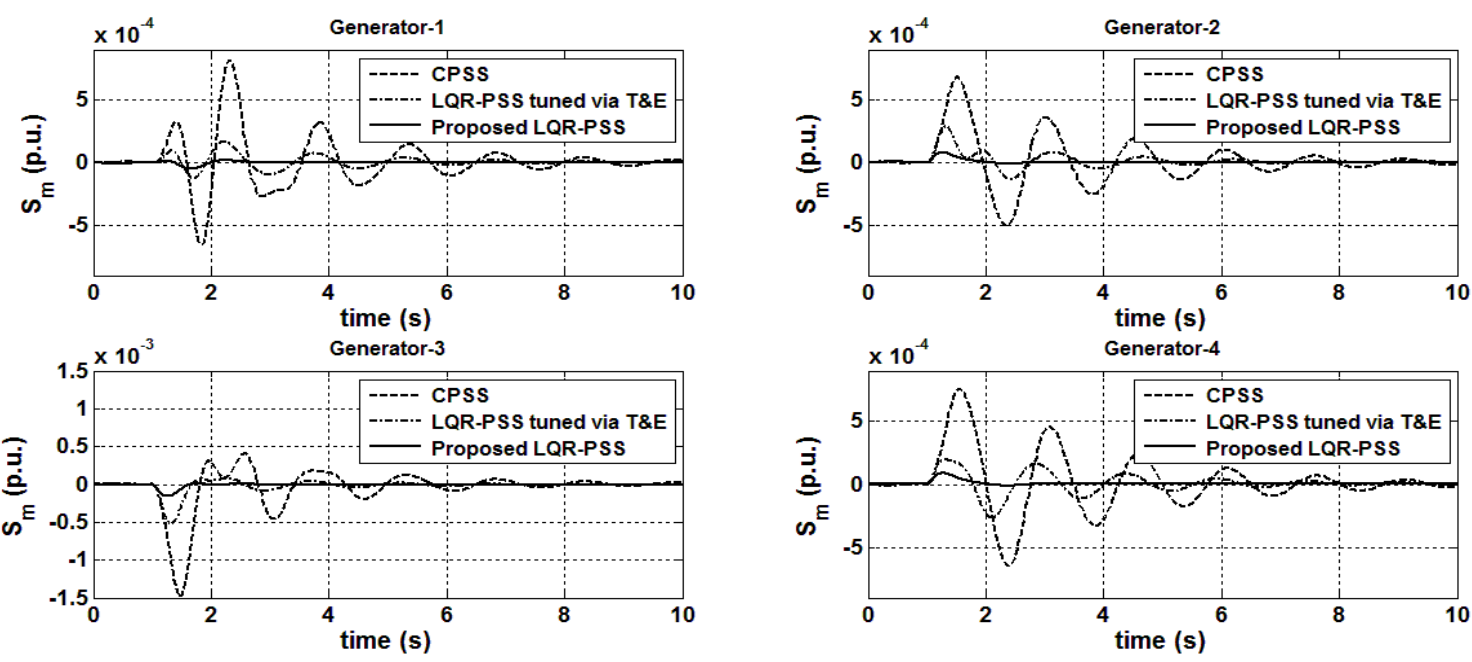

Figure 4. Variation in slip $\left(S_{m}\right)$ when generator $G_{3}$ operating at $120 \%$ of nominal load is subjected to $10 \%$ increase in voltage with tie line power flow of $400 \mathrm{MW}$

\section{CONCLUSION}

In contrast with the LQR tuning via the trial-and-error approach, the LQR tuning via the proposed analytical approach leads to enhanced robustness of the power system as the state weighting matrix $Q$ varies in line with the operating condition in the proposed methodology. The simulation results proved the superiority of the proposed optimal LQR in damping low-frequency electromechanical oscillations. It is observed that the proposed LQR improved the system dynamics by reducing the settling time and overshoots/undershoots.

\section{REFERENCES}

[1] R. J. Fleming and J. Sun, "An optimal multivariable stabilizer for a multimachine plant," IEEE Transactions on Energy Conversion, vol. 5, no. 1, pp. 15-22, Mar. 1990, doi: 10.1109/60.50806.

[2] D. Arnautovic and J. Medanic, "Design of Decentralized Multivariable Excitation Controllers in Multimachine Power Systems by Projective Controls," IEEE Transactions on Energy Conversion, vol. EC-2, no. 4, pp. 598-604, Dec. 1987, doi: 10.1109/TEC.1987.4765898.

[3] Y.-N. Yu, K. Vongsuriy, and L. N. Wedman, "Application of an Optimal Control Theory to a Power System," IEEE Trans. on Power Apparatus and Systems, vol. PAS-89, no. 1, pp. 55-62, Jan. 1970, doi: 10.1109/TPAS.1970.292668.

[4] H. A. M. Moussa and Y.-N. Yu, "Optimal Power System Stabilization Through Excitation and/or Governor Control," IEEE Power Engineering Society for presentation at the IEEE Summer Meeting and International Symposium on High Power Testing, Portland, Ore., vol. PAS-91, no. 3, pp. 1166-1174, May 1972, doi: 10.1109/TPAS.1972.293473.

[5] Y.-Y. Hsu and C.-Y. Hsu, "Design of a Proportional-Integral Power System Stabilizer," IEEE Transactions on Power Systems, vol. PWRS-1. no. 2, pp. 46-52, May 1986, doi: 10.1109/TPWRS.1986.4334898.

[6] S. Hirano, T. Michigami, A. Kurita, D. B. Mapper, and N. W. Miller, "Functional design for a system-wide multivariable damping controller," IEEE Transactions on Power Systems, vol. 5, no. 4, pp. 1127-1136, Nov. 1990, doi: 10.1109/59.99362.

[7] A. V. Reddy, M. V. Kumar, I. Sen, and G. Gurrala, "Decentralized linear quadratic power system stabilizers for multi-machine power systems," Indian Academy of Sciences, Sadhana, vol. 37, no. 4, pp. 521-537, Aug. 2012, doi: 10.1007/s12046-012-0091-3.

[8] L. Yathisha and S. Patilkulkarni, "LQR and LQG based optimal switching techniques for PSS and UPFC in power systems," Springer-Control Theory and Technology, vol. 16, no. 1, pp. 25-37, Jan. 2018, doi: 10.1007/s11768-018-6174-x.

[9] A. E. Bryson and Y.-C. Ho, "Applied Optimal Control: Optimization, Estimation, and Control," Hemisphere Publishing Corporation, John Wiley \& Sons, 1975.

[10] A. V. Reddy, M. V. Kumar, and G. Gurrala, "Novel Approach for the Design of State Feedback Power System Stabilizers," IEEE International Conference on Power System Technology-(POWERCON 2010), 24-28 Oct. 2010, doi: 10.1109/POWERCON.2010.5666494.

[11] I. Robandi, K. Nishimori, R. Nishimura, and N. Ishihara, "Optimal feedback control design using genetic algorithm in multimachine power system," Elsevier, International Journal of Electrical Power and Energy Systems, vol. 23, no. 4, pp. 263-271, May 2001, doi: 10.1016/S0142-0615(00)00062-4.

[12] M. I. Solihin and R. Akmeliawati, "Particle Swam Optimization for Stabilizing Controller of a Self-erecting Linear Inverted Pendulum,” International Journal of Electrical and Electronic Systems Research, vol. 3, pp. 13-23, Jun. 2010.

[13] M. Almobaied, I. Eksin, and M. Guzelkaya, "Design of LQR Controller with Big Bang-Big Crunch Optimization Algorithm Based on Time Domain Criteria," IEEE-24th Mediterranean Conference on Control and Automation (MED), Athens, Greece, Jun. 2016, pp. 1192-1197, doi: 10.1109/MED.2016.7535907.

[14] A. Jacknoon and M. A. Abido, "Ant Colony Based LQR and PID tuned Parameters for Controlling Inverted Pendulum," IEEE International Conference on Communication, Control, Computing and Electronics Engineering (ICCCCEE), Khartoum, Sudan, Jan. 2017, doi: 10.1109/ICCCCEE.2017.7867652.

[15] S. Das, I. Pan, K. Halder, S. Das, and A. Gupta, "LQR based improved discrete PID controller design via optimum selection of weighting matrices using fractional order integral performance index," Elsevier, Applied Mathematical Modelling, vol. 37, pp. 4253-4268, Mar. 2013, doi: 10.1016/j.apm.2012.09.022. 
[16] M. Jokarzadeh, M. Abedini, and A. Seifi, "Improving Power System Damping Using a Combination of Optimal Control Theory and Differential Evolution Algorithm," Elsevier-ISA Transactions, vol. 90, pp. 169-177, Jul. 2019, doi: 10.1016/j.isatra.2018.12.039.

[17] A. Akbarimajd, S. Asefi, and H. Shayeghi, "Using Jaya Algorithm to Optimal Tuning of LQR Based Power System Stabilizers," IEEE $2^{\text {nd }}$ International Conference on Computational Intelligence and Applications (ICCIA), Sep. 2017, pp. 482-486, doi: 10.1109/CIAPP.2017.8167264.

[18] B. M. Alshammari, "Optimal Design of Multimachine Power System Stabilizers using Gbest-guided Artificial Bee Colony Algorithm," International Journal of Engineering Research \& Technology (IJERT), vol. 5, no. 4, pp. 330-338, Apr. 2016, doi: IJERTV5IS040512.

[19] N. N. Islam, M. A. Hannan, H. Shareef, and A. Mohamed, "An Application of Backtracking Search Algorithm in Designing Power System Stabilizers for Large Multi-machine System," Elsevier - Neurocomputing, vol. 237, pp. 175-184, May 2017, doi: 10.1016/j.neucom.2016.10.022.

[20] T. K. Roy, M. A. Mahmud, and A. M. T. Oo, "Robust Adaptive Backstepping Excitation Controller Design for Higher-Order Models of Synchronous Generators in Multimachine Power Systems," IEEE Transactions on Power Systems, vol. 34, no. 1, pp. 40-51, Jan. 2019, doi: 10.1109/TPWRS.2018.2868783.

[21] B. Dasu, M. Sivakumar, and R. Srinivasarao, "Interconnected multi-machine power system stabilizer design using whale optimization algorithm," Springer Open - Protection and Control of Modern Power Systems, vol. 4, no. 2, pp. 1-11, Feb. 2019, doi: 10.1186/s41601-019-0116-6.

[22] B. Dasu, M. Sivakumar, and R. Srinivasarao, “An improved whale optimization algorithm for the design of multi-machine power system stabilizer," Wiley-International Transactions on Electrical Energy Systems, vol. 30, no. 5, pp. 1-29, Jan. 2020, doi: 10.1002/2050-7038.12314.

[23] N. Yousefi, "Multi-stage Fuzzy Power System Stabilizer based on Modified Shuffled Frog Leaping Algorithm," Bulletin of Electrical Engineering and Informatics, vol. 4, no. 3, pp. 176-185, Jan. 2015, doi: 10.11591/eei.v4i3.500.

[24] M. A. A. Ghany and M. A. Shamseldin, "Model reference self-tuning fractional order PID control based power system stabilizer," International Journal of Power Electronics and Drive System (IJPEDS), vol. 11, no. 3, pp. 1333-1343, Sep. 2020, doi: 10.11591/ijpeds.v11.i3.pp1333-1343.

[25] N. A. M. Kamari, I. Musirin, Z. A. Hamid, and M. N. A. Rahim, "EP-Based Optimisation for Estimating Synchronising and Damping Torque Coefficients," Energy and Power, vol. 2, no. 2, pp. 17-23, 2012, doi: 10.5923/j.ep.20120202.03.

[26] G. Gurrala and I. Sen, "Power System Stabilizers Design for Interconnected Power Systems," IEEE Trans. on Power Systems, vol. 25, no. 2, pp. 1042-1051, Feb. 2010, doi: 10.1109/TPWRS.2009.2036778.

[27] K. Ogata, "Modern Control Engineering," Pearson India Education Services Pvt. Ltd., $5^{\text {th }}$ ed, 2016.

[28] K. R. Padiyar, "Power System Dynamics: Stability and Control," BS Publications, 2 $2^{\text {nd }}$ ed, 2008.

\section{BIOGRAPHIES OF AUTHORS}
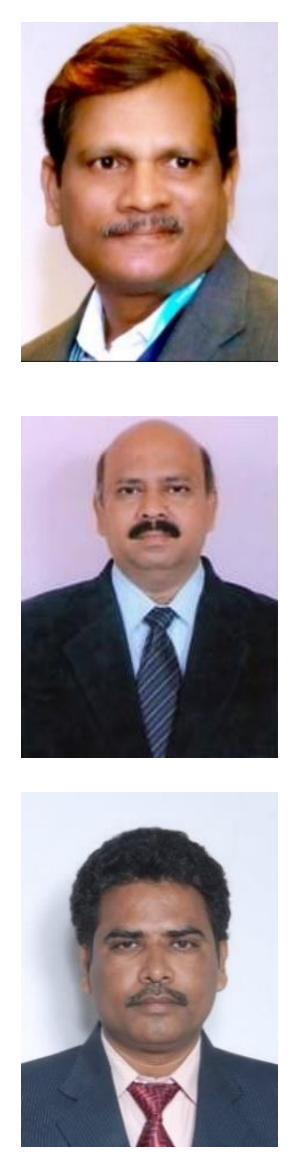

Mr. Sreenivas Uravakonda (D) SA SC P graduated in Electrical and Electronics Engineering from JNTU, Hyderabad, India in 1991. He has been Electrical Engineer with Penna Cements, AP, India from 1991 to 1996, Senoir Electrical Engineer with APCW, L\&T, AP, India from 1996 to 2000, Assistant Professor in various engineering colleges affiliated to JNTU, Hyderabad, India from 2000 to 2009. He obtained M.Tech. PG degree in 'Electrical Power Systems' from JNTU, Hyderabad, India in 2008. He has been Professor/Vice-Principal from 2009 to 2021 in various engineering colleges affiliated to JNTU, Anantapur, AP, India. Currently working as Associate Professor in Electrical Engineering, Srinivasa Ramanujan Institute of Technology, Ananthapuramu, JNTUA, Anantapur, A.P., India. He can be contacted at email: uravakonda.sreenivas@gmail.com.

Prof. Vijaya Kumar Mallapu (D) 8d SC P graduated in Electrical and Electronics Engineering from S.V. University, Tirupathi, A.P, India in 1988. He obtained M.Tech degree in 'Electrical Machines \& Industrial Drives' from Regional Engineering College (NITW), Warangal, India in 1990. He received Ph.D. degree in Electrical Engineering from JNTU, Hyderabad, India in 2000. Currently he is working as Professor in Electrical \& Electronics Engineering and Rector, JNT University Anantapur, A.P, India. His research interests include Electrical Machines, Electrical Drives, Microprocessors and Power Electronics. He has authored or co-authored more than 200 journal and conference papers. He can be contacted at email: mvk.eee@jntua.ac.in.

Dr. Venkateswara Reddy Annapu Reddy (D) 81 SC P received B.E. degree in Electrical and Electronics Engineering from Karnataka University, Dharwad, Karnataka, India in $1996 . \mathrm{He}$ obtained M. Tech. in 2005 from JNTU, Hyderabad, India. He received Ph.D. degree in Electrical Engineering from JNTU, Anantapur, AP, India in 2015. He has been Professor of Electrical Engineering in several engineering colleges affiliated to JNTUA, Anantapur, AP, India since 2000. He is currently the Vice-Principal of Sai Rajeswari Institute of Technology, Proddatur, Kadapa, AP, India. He has authored and co-authored about 30 referred journals and IEEE conference papers with Elsvier and Springer. His research interests include the power system stability, FACTS devices, and power system optimization. He can be contacted at e-mail: avreddyeee@gmail.com. 